ing: evaluation of flow characteristics and size. J THORAC Cardiovasc Surg 1993;106:579-86.

4. Calabuig R, Moody FG. Abdominal cavity: anatomy and structural anomalies. In: Yamada T, ed. Textbook of gastroenterology. Philadelphia: JB Lippincott, 1991:2045-56.

\section{Successful correction of Ebstein's anomaly with rheumatic mitral valvular disease}

\section{To the Editor:}

Anomalies of the left side of the heart associated with Ebstein's malformation of the tricuspid valve occur occasionally. Mitral valve abnormalities that have been reported include valvular stenosis, parachute mitral valve, mitral valve prolapse, supravalvular ring, cleft mitral leaflet in association with endocardial cushion defects, coarctation of the aorta, and other defects. A combination of Ebstein's anomaly with rheumatic mitral valvular disease is still a rarity. We report here a case of rheumatic mitral valvular lesion and Ebstein's anomaly, successfully treated with tricuspid and mitral valve replacements. Successful treatment of this combination of lesions has not been reported previously to our knowledge.

An 11-year-old Kenyan boy weighing $25.5 \mathrm{~kg}$ was admitted with a history of frequent cough and palpitations of 7 years' duration. There was a history of dyspnea on exertion and paroxysmal nocturnal dyspnea since the age of 3 years, and of pain on the left side of the chest, puffiness of the face, and edema of the lower limbs since the age of $3 \frac{1}{2}$ months. Clinical examination revealed clubbing and pallor. Heart rate was 98 beats $/ \mathrm{min}$ and regular. Jugular venous pulsations were within normal limits. Blood pressure was $90 / 70 \mathrm{~mm} \mathrm{Hg}$. Apex beat was in the left sixth intercostal space, outside the midclavicular line. The first heart sound was normal; the pulmonary component of the second heart sound was loud. Auscultation findings suggested mitral stenosis with regurgitation and tricuspid regurgitation. The liver was $4 \mathrm{~cm}$ below the right costal margin and pulsatile. Results of routine blood and urine investigations were within normal limits. A chest radiograph showed significant cardiomegaly, with a narrow pedicle and normal pulmonary blood flow. There was mitralization of the left heart border. Electrocardiogram showed normal sinus rhythm, with right and left atrial enlargement. Echocardiography revealed trabeculated right ventricle with Ebstein's anomaly of the tricuspid valve. There was moderate tricuspid regurgitation. The mitral valve had a restricted opening, with doming of the leaflets associated with mitral regurgitation. Cardiac catheterization confirmed the echocardiographic findings, and the characteristic cloverleaf appearance of the tricuspid valve could be discerned (Fig. 1). The catheterization data are given in Table I. The diagnosis of Ebstein's anomaly with moderate tricuspid regurgitation and rheumatic mitral stenosis with regurgitation (Fig. 2) was established. The patient was taken in for surgical correction. Surgical exposure was through a median sternotomy. Cardiopulmonary bypass was achieved by cannulation of the aorta, superior vena cava, and inferior vena cava. The patient was cooled to $25^{\circ}$ C. Cold blood cardioplegia was used to achieve cardioplegic arrest; topical hypothermia with normal saline solution was used in addition. The tricuspid anulus was extremely large, with a perforated anterior leaflet. It was therefore decided to replace the valve with a $3 \mathrm{M}$ Starr-Edwards valve (Baxter Healthcare Corp., Edwards Division, Santa Ana, Calif.) attached with continuous 2-0 polypropylene sutures in a supracoronary position. The aneurysmal part of the atrialized right ventricular portion was also plicated. The mitral valve was excised and

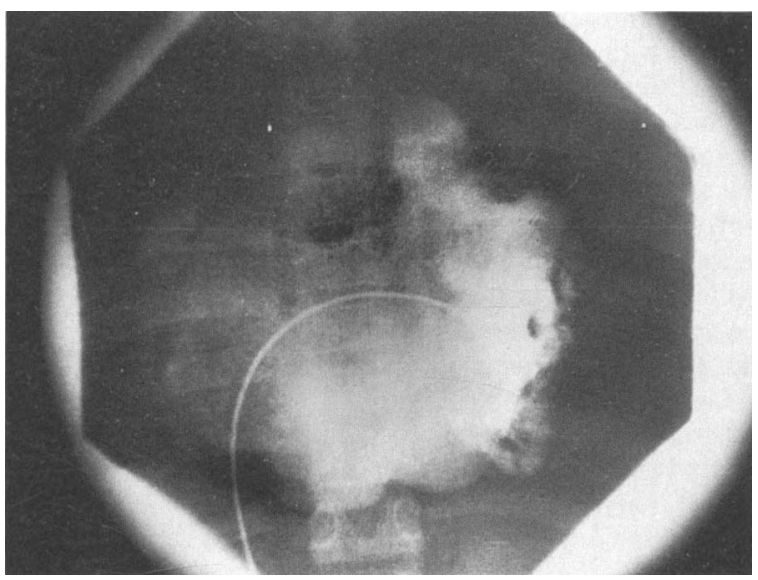

Fig. 1. Angiocardiogram shows the typical cloverleaf deformity of Ebstein's anomaly.

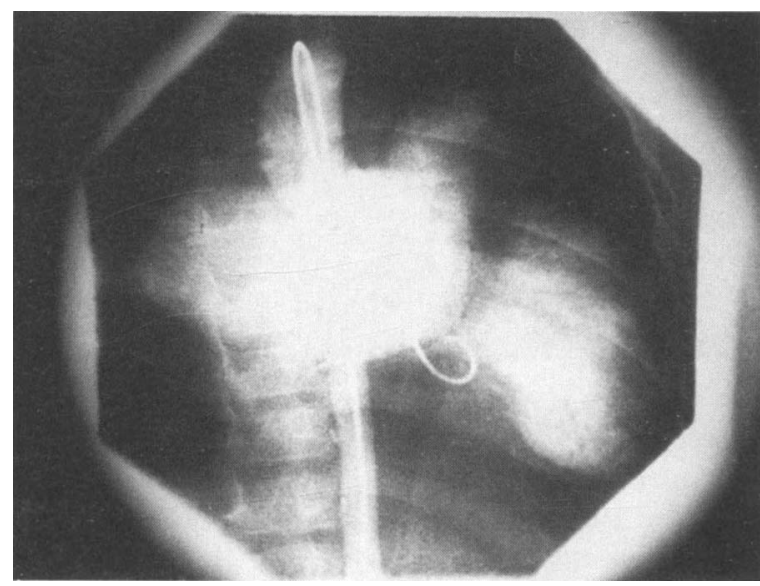

Fig. 2. Angiocardiogram shows gross mitral regurgitation.

Table I. Hemodynamic data

\begin{tabular}{lcc}
\hline & & Pressure in $\mathrm{mm} \mathrm{Hg}$ \\
\cline { 3 - 3 } \multicolumn{1}{c}{ Site } & Oxygen saturation & Syst/dias (mean) \\
\hline HSVC & 43.8 & \\
IVC & 23 & \\
MRA & 32.6 & $18 / 16(14)$ \\
MRV & 34.1 & $38 / 12$ \\
PA & 33.6 & $38 / 12(25)$ \\
LPW & & $32 / 35(25)$ \\
LV & 97 & $100 / 8$ \\
AA & 95.4 & $100 / 68(83)$ \\
FA & & $112 / 70(82)$ \\
RV-RA gradient & & 3 \\
PA-RV gradient & & 0 \\
LV-AO gradient & & 0 \\
PW-LVEDP gradient & & 17 \\
\hline
\end{tabular}

$H S V C$, High superior vena cava; $I V C$, inferior vena cava; $M R A$, mid right atrium; $M R V$, mid right ventricle; $P A$, pulmonary artery; $L P W$, left pulmonary wedge pressure; $L V$, left ventricle; $A A$, ascending aorta: $F A$, femoral artery; $R V$, right ventricle; $R A$, right atrium; $A O$, aorta; $L V E D P$, left ventricular enddiastolic pressure. 
replaced with a $2 \mathrm{M}$ Starr-Edwards valve. This was sutured into position with continuous 2-0 polypropylene sutures. Cardiac rhythm was obtained by a single direct-current shock after routine deairing and release of the aortic crossclamp. Chest closure was achieved in the usual manner after inserting a right atrial line, a left atrial line, and atrioventricular pacing wires. Except for transient rhythm disturbance in the immediate postoperative period, which was well controlled by antiarrhythmics, postoperative recovery was uneventful. The patient was discharged on the tenth postoperative day in sinus rhythm. Ten months after the operation, he continues to do well.

Ebstein's anomaly alone constitutes only $1 \%^{1}$ of the congenital heart diseases, with a wide spectrum of deformity of the tricuspid valve. Ebstein's anomaly usually occurs as an isolated lesion. ${ }^{2}$ Association of Ebstein's anomaly with a rheumatic mitral valve lesion was reported from India by Mohan and Tandon. ${ }^{3}$ Medical treatment has little to offer the patient except for the control of arrhythmias and congestive heart failure. It has been our experience that valves suitable for repair are rare, especially when there is significant tricuspid regurgitation. Repair based on a large anterior tricuspid leaflet is preferred to valve replacement whenever feasible because it avoids the problem of prosthetic valve dysfunction, anticoagulation, and (in children) the need for a later replacement because of growth. ${ }^{4}$ Melo and colleagues ${ }^{5}$ and Najafi and associates ${ }^{6}$ report excellent long-term results in Ebstein's anomaly with the Starr-Edwards valve. ${ }^{6}$ In cases with associated mitral stenosis and pulmonary hypertension with tricuspid regurgitation, which could be aggravated by Ebstein's anomaly, replacement of the tricuspid valve may be preferable to repair.

Premanand Ponoth, $M S, M C h$

S. Rajan, $M S, M C h$

Suresh G. Rao, $M S, M C h$

K. M. Cherian, $M S, F R A C S$

Institute of Cardiovascular Diseases Vadapalani, Madras, India

\section{R E F ER E N C ES}

1. Kirklin JW, Barratt-Boyes BG. Cardiac surgery. New York: John Wiley, 1986:889-909.

2. Gentar R, Blount SG Jr. The spectrum of Ebstein's anomaly [Abstract]. Am Heart J 1967;73:395.

3. Mohan JC, Tandon R. Ebstein's anomaly of the tricuspid valve associated with rheumatic mitral stenosis. Indian Heart J 1987;39:67-8.

4. Danielson GK, Fuster V. Surgical repair of Ebstein's anomaly. Ann Surg 1982;196:499-504.

5. Melo J, Saylam A, Knight R, Starr A. Long-term results after surgical correction of Ebstein's anomaly: report of two cases. J THORAC CARDIOvasc SuRG 1979;78:233.

6. Najafi $H$, Hunter JA, Dye WS, Javid $H$, Julian OC. Ebstein's malformation of the tricuspid valve. Ann Thorac Surg 1967;4:334-43.

\section{Thrombosis after the Fontan procedure: Transesophageal echocardiography may replace angiocardiography}

\section{To the Editor:}

Thrombosis of the right side of the heart after a Fontan procedure remains a serious complication with a high mortality and, at the same time, a diagnostic and therapeutic challenge. The article by Hedrick and colleagues ${ }^{1}$ has highlighted these aspects. They provide an excellent overview of cases thus far reported and emphasize the difficulties in diagnosing the condition. They also promote routine echocardiographic surveillance after the Fontan operation and angiocardiographic studies once thrombosis is suspected. We would like to amend this approach by suggesting that transesophageal echocardiography presently is the diagnostic tool par excellence and, in fact, eventually may replace angiocardiography.

A 3-year-old boy with univentricular heart, mitral atresia, and pulmonary stenosis, who previously had atrial balloon septostomy (at the age of 2 months) and atrial blade septostomy (at the age of 2 years) as palliative procedures, underwent a fenestrated Fontan operation. The pulmonary artery was transected, the right atrial appendage connected to the right pulmonary artery at the site of the bifurcation, and a tunnel created to direct the blood from the caval veins to the pulmonary artery. An intraoperative transesophageal echocardiogram showed unobstructed flow into the pulmonary arteries (Fig. 1, $A$ ). The patient was not given anticoagulants. On the second postoperative day right-sided pleural effusion was diagnosed, and on day 3 the patient had massive diarrhea associated with thrombopenia. Within a few hours after this event, a sharp rise in the central venous pressure occurred accompanied by extreme distention of the jugular veins and swelling of the liver. Thrombotic occlusion was suspected, but the precordial echocardiograms were inconclusive. The decision was made to evaluate the condition with the use of transesophageal echocardiography.

With the child awake, a prototypical Aloka $4 \mathrm{~mm}$ catheter (Aloka Incorporated, Tokyo, Japan) was introduced into the esophagus after the nose was sprayed with a local anesthetic. The echographic pictures obtained nicely portrayed the site of the bifurcation of the pulmonary arteries, but, despite clear visualization of nonobstructed flow via the anastomosis between the right atrial appendage and the right pulmonary artery, no flow was seen in the left pulmonary artery (Fig. 1,B). At the time this was considered to be an artifact resulting from the projection of the left pulmonary artery. Nevertheless, the patient underwent immediate reoperation without further heart catheterization. The fenestration was enlarged and thrombi were removed from the systemic venous atrium. After the child was weaned from cardiopulmonary bypass, transesophageal echocardiography once again failed to show flow in the left pulmonary artery, but a thrombus was recognized (Fig. 1, C). Bypass was reinstituted, the left pulmonary artery was opened, and a massive thrombus occluding the left main pulmonary artery was found and removed. The patient was then weaned from cardiopulmonary bypass without difficulties. Transesophageal echocardiography in the immediate postoperative period demonstrated flow in both pulmonary arteries and no residual obstructions.

Although our present experience was obtained retrospectively, it endorses previous studies indicating the superiority of transesophageal echocardiography over conventional echocardiographic approaches for the detection of thrombus formation after the Fontan operation. ${ }^{2,3}$ Technical achievements in miniaturizing the probes have made the transesophageal approach accessible for infants and children. In fact, a $4 \mathrm{~mm}$ diameter probe can now be inserted through the nose under local anesthesia, as documented in this case. Hence it appears that transesophageal echocardiography in patients with evidence of 